\title{
Spatial variation in size at onset of maturity of female southern rock lobster Jasus edwardsii around Tasmania, Australia
}

\author{
CALEB GARDNER, STEWART FRUSHER, NEVILLE BARRETT, MALCOLM HADDON \\ and COLIN BUXTON
}

Tasmanian Aquaculture and Fisheries Institute, University of Tasmania, Private Bag 49, Hobart 7000, Australia.

E-mail: Caleb.Gardner@utas.edu.au

\begin{abstract}
SUMMARY: The size at onset of maturity (SOM) of female Jasus edwardsii (Hutton, 1875) was estimated at 50 sites around Tasmania, Australia, based on the presence of ovigerous setae. There was a distinct spatial cline with the largest SOM being found at northwestern sites and the smallest at southwestern sites. Variation in SOM between sites was substantial and ranged from $59 \mathrm{~mm}$ to $112 \mathrm{~mm}$ carapace length. The observed decline in SOM from north to south was the reverse of that described for the same species at similar latitudes in New Zealand, which suggests that SOM in J. edwardsii is regulated by factors in addition to temperature. The effect of density on female SOM was investigated by comparing SOM estimates from two marine reserves with adjacent fished sites; however, there was no evidence of a decline in SOM with increasing density as predicted. A model of SOM predicted by latitude and longitude is described to facilitate spatial modelling of lobster stocks. The substantial and predictable spatial variation in SOM implies that management of this fishery would be improved by incorporating spatial elements, such as regional legal minimum size limits.
\end{abstract}

Keywords: Jasus edwardsii; maturity; rock lobster; reproduction; spatial management.

RESUMEN: VARIACIÓN ESPACIAL EN LA TALLA DE INICIO DE MADUREZ EN HEMBRAS DE LANGOSTA, JASUS EDWARDSII, EN TASMANIA, AUSTRAliA. - En 50 sitios alrededor de Tasmania (Australia) se estimó la talla de inicio de madurez sexual (SOM) en hembras de Jasus edwardsii (Hutton, 1875) basándose en la presencia de sedas ovígeras. La mayor SOM fue observada en la región del Noroeste y la talla menor en el Suroeste. La SOM varió entre $59 \mathrm{~mm}$ y $112 \mathrm{~mm}$ en longitud del caparazón. La disminución en la SOM desde el norte hacia sur fue inversa a la descrita previamente para la misma especie en similares latitudes en Nueva Zelanda. Esto sugeriría que la SOM en hembras de J. edwardsii es regulada por otros factores además de la temperatura. El efecto de la densidad de langostas en la SOM de hembras de J. edwardsii fue comparado usando SOM estimadas a partir de sitios con alta (reservas marinas) y baja densidad (sitios de pesca) de langostas. El incremento en la densidad no disminuyó la SOM como fue previamente predicho. Para mejorar y facilitar los modelos sobre los stocks de langostas, se describe un modelo para predecir la SOM que incorpora la latitud y la longitud como componentes espaciales. Dado que la SOM depende substancialmente y de manera predecible de las variaciones espaciales, el manejo de la pesquería de J. edwardsii podría ser mejorado con la incorporación de componentes espaciales a los planes de manejo, como por ejemplo establecer regionalmente un tamaño límite legal.

Palabras clave: Jasus edwardsii, madurez, langosta, reproducción, gestión espacial.

\section{INTRODUCTION}

The Tasmanian rock lobster fishery is based almost entirely on Jasus edwardsii with around 1500 tonnes landed each year by the commercial fleet and another 150 tonnes by the recreational sector. A feature of this fishery is the large spatial variation in growth rates, with growth increments of females from northern areas around $10 \mathrm{~mm}$ per annum at minimum legal size $(105 \mathrm{~mm}$ carapace 
length (CL)), while those in the south average growth increments of less than $1 \mathrm{~mm}$ per annum at $105 \mathrm{~mm}$ CL (Punt et al., 1997). Size at onset of maturity (SOM) in female lobsters is considered to be age-specific rather than size-specific so this spatial trend in growth around Tasmania was also reflected in SOM (Pollock and Goosen, 1991).

Information on spatial variation in female SOM around Tasmania was analysed here. This contributes to fisheries management because the reproductive output of stocks is used as a performance measure in the Tasmanian fishery. Broad regional analyses of SOM were used as input parameters for assessment modelling of the Tasmanian resource by Punt and Kennedy (1997). Results of this model showed that egg production is variable regionally with some areas being virtually unaffected by fishing while other areas were highly depleted with egg production below $15 \%$ of virgin. A management objective since 1998 has been to rebuild egg production to above target levels of $25 \%$ of virgin in all regions of this fishery. However, this has not been achieved despite management changes that have promoted stock rebuilding for the State as a whole (Gardner et al., 2005a). As a result, current management discussions are increasingly focused on spatial management options and improved spatial information on SOM is required to inform these discussions.

Variation in SOM may result from the influence of a range of factors such as depth, temperature, density and food availability. We attempted to examine the basis for observed differences in SOM between sites by examining patterns in relation to depth, latitude and longitude, and density. The possible influence of density is of special interest because it is manipulated by changes in fisheries management. The issue of density-dependent effects on exploited species has been recognised for decades as being important for fisheries modelling even though it is typically difficult to examine (Haddon, 2001). Analyses presented here for $J$. edwardsii contrasted estimates of SOM from marine protected areas (MPAs) and adjacent fished sites.

Changes in population dynamics due to density is currently of much interest for Australian lobster management because of increased coverage of MPAs. Elevated density of lobsters inside an MPA is generally interpreted to mean an increase in reproductive output, although potential changes to SOM in response to density would be expected to moderate or alter the extent of any change. Evaluating the impact of MPAs on the entire resource, including both fished and unfished areas, has only been accomplished through modelling where processes such as displacement of effort and spatial differences in stocks can be assessed. Although this type of model-based research has been conducted on southern rock lobster stocks, these analyses did not consider density dependent changes in SOM (Gardner et al., 2000; Hobday et al., 2005). The effect of increased density on SOM was investigated here to inform future population modelling. We note that although a decline in SOM with increased density inside MPAs would be predicted, this cannot be assumed. For example, elevated density within an MPA led to increased rather than decreased growth rates in the Caribbean spiny lobster Panulirus argus (Latreille), apparently due to concurrently improved habitat conditions (Davis and Dodrill, 1989).

\section{METHODS}

\section{Sample sites and specimen collection}

A total of 141685 female rock lobsters Jasus edwardsii were collected using baited traps set from commercial and research vessels from 1963 to 2002. Data were collected for general stock assessment purposes rather than research targeted at collecting maturity data. Sites for sampling were distributed around the Tasmanian coast covering most areas important to lobster fishing. All sites used here were sampled on more than two occasions, usually over a period of several years. Size of females was recorded as carapace length $(\mathrm{CL}$, the distance from the base of the antennal platform to the dorsal, posterior margin of the carapace along the midline). The females were classified as mature based on the development of ovigerous setae on the endopodite of pleopods (Gardner et al., 2005b). In some cases, pleopods had slight development of setae and observers classed these animals as "partially setose"; these were classed as immature for analyses conducted here. The latitude, longitude and depth from each site were based on the midpoint of all trap locations recorded at the site.

Comparison of the effect of density on SOM was made at two marine protected areas (MPA) in the south east of the State, Maria Island MPA $\left(148.058^{\circ} \mathrm{E}, 42.578^{\circ} \mathrm{S}\right)$ and Crayfish Point MPA $\left(147.353^{\circ} \mathrm{E}, 42.952^{\circ} \mathrm{S}\right)$. Estimated SOM from the 
Maria Island MPA was compared with those from nearby fished sites at Point Lesueur $\left(148.007^{\circ} \mathrm{E}\right.$, $\left.42.659^{\circ} \mathrm{S}\right)$, Hellfire Bluff $\left(147.933^{\circ} \mathrm{E}, 42.740^{\circ} \mathrm{S}\right)$, Boy in the Boat $\left(148.025^{\circ} \mathrm{E}, 42.741^{\circ} \mathrm{S}\right)$ and Cape Mauraoud $\left(148.133^{\circ} \mathrm{E}, 42.666^{\circ} \mathrm{S}\right)$ on the east coast of Tasmania. Density of lobsters in the Maria Island MPA was estimated using diver transects in 1997 by Edgar and Barrett (1999) and found to be around $260 \%$ higher relative to nearby fished sites including Point Lesueur and Boy in the Boat. A further relative increase in density at the Maria Island MPA was recorded between the time of those diver surveys and the collection of the SOM data from Maria Island MPA presented here (2000, 2001 and 2002; Buxton et al., 2004). Estimated SOM from the Crayfish Point MPA was contrasted with that from Glenvar Point $\left(147.397^{\circ} \mathrm{E}, 43.008^{\circ} \mathrm{S}\right)$, an area popular with recreational fishers. Diver transects at the Crayfish Point MPA in 2000 by Ziegler et al. (2002) led to similar estimates of density to those from Maria Island MPA made by Edgar and Barrett (1999; 4.75 per $100 \mathrm{~m}^{2}$ and 5.6 per $100 \mathrm{~m}^{2}$ respectively). No transect data are available from the fished site at Glenvar Point although density of legal-sized lobsters is clearly much reduced by recreational fishing; a 3 day survey by 4 divers at Glenvar Point in 2002 captured 615 lobsters, only 2 of which were above the minimum legal size, while over $50 \%$ of lobsters observed by Ziegler et al. (2002) were above the minimum legal size at the nearby $(5 \mathrm{~km})$ Crayfish Point MPA.

\section{Data analyses}

As sample data were collected over 40 years, there was a risk of potential bias due to sampling variation in years, vessels and sampling personnel. This risk was examined by OLSE regression of year of sampling relative to latitude, longitude and their interaction $\left(\mathrm{H}_{\mathrm{o}}: \hat{\beta}_{2}=0\right)$.

Sample sizes at each site were variable and ranged between 119 and 34028 females. Data were analysed from 81 sites although it was not possible to obtain reliable estimates of SOM from 31 of these. This inability to produce reliable estimates of SOM occurred in some instances due to small sample sizes. In some of the southern sites, samples contained few immature animals due to their smaller SOM and selectivity of traps (Ziegler et al., 2002). Hence, despite large samples of several hundred animals, poor model fits were obtained on occasion as samples contained mainly mature females. These analyses were excluded from the results presented here.

The proportion of females that were classed mature $(\mathrm{P})$ was modelled for each site with a logistic function of the form: $P=e^{(a+b x)} /\left(1+\mathrm{e}^{(a+b x)}\right)$, maximising the log likelihood derived from using the logit transformation (Neter et al., 1990). These models were then used to estimate the size at which $50 \%$ and $95 \%$ of the population were mature (L50\% and L95\%). Estimation of uncertainty around these estimates followed the method of Turner et al. (2002). This determined 95\% confidence limits around model fits from 1000 simulations for each area in a bootstrapping routine where data were randomly sampled with replacement from each of the size bins (Haddon, 2001). The middle 95\% of the bootstrap replicates constituted the confidence interval. Confidence limits derived by this method reflect the uneven distribution of certainty around estimates of SOM; we typically had less certainty towards the lower bound due to smaller sample sizes of individuals classed as immature compared to those classed as mature.

The effects of latitude, longitude, depth and interactions on SOM were analysed using standard least square regression on the estimates of SOM from each of the 50 sites.

\section{RESULTS}

Testing of temporal bias of data indicated a significant trend in timing of sampling in relation to latitude and longitude $(\mathrm{n}=50, \mathrm{P}<0.05, \mathrm{~F}$ ratio $=5.35)$. The significant result appeared to be largely a function of the sample size (50 sites) because the effect size was small with slope estimates of $\hat{\beta}_{2}{ }^{\text {lat }}=-0.39$, $\hat{\beta}_{2}^{\text {long }}=-0.42$ and $\hat{\beta}_{2}^{\text {lat } \times \text { long }}=0.75$. Given that samples ranged in latitude and longitude by 3 degrees, this implies a systematic bias in the timing of sampling across the region of less than 3 years, relative to the temporal span in sample data of 40 years. This was considered to be of a magnitude unlikely to bias subsequent analyses of SOM in relation to location.

Standard least squares regression indicated that the factors of depth, depth $\times$ latitude, and depth $\times$ longitude did not significantly affect L50\% (P>0.12). These factors were subsequently removed from the full model and the effect of the remaining factors examined. Latitude, longitude and their interaction 


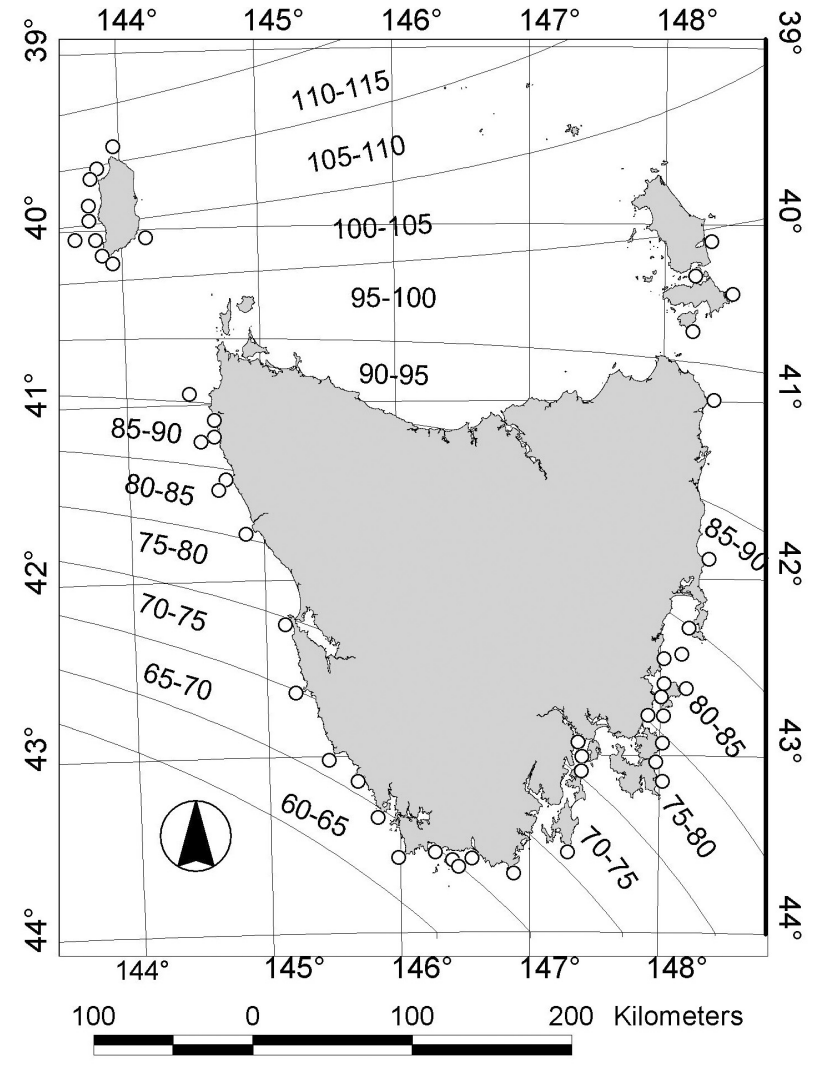

FIG. 1. - Spatial variation in L50\% for female southern rock lobsters Jasus edwardsii around Tasmania. The 50 sample sites where estimates of L50\% were collected are shown by points. Contour lines indicate the continuum of changing SOM with latitude and longitude as estimated by regression against latitude and longitude of the sites shown.

appeared to have a significant and substantial influence on L50\% (F-ratio and probability respectively: $99.8,<0.0001 ; 13.4,<0.001 ; 13.5,<0.001)$.

Examination of individual sites showed that we had low resolution for detecting an effect of depth on the SOM. That is, although there was an extensive range in sites from different latitudes and longi- tude, there were few instances where there was contrast in depths between sites at similar locations. Furthermore, depth of fishing was correlated with latitude with most deep-water sites in the south of the State. Thus there was low power to detect an effect of depth and we acknowledge that a reasonable risk exists of a type II error in concluding there was no effect of depth.

Given the apparent importance of latitude, longitude and their interaction, a linear model based solely on these factors was used to estimate parameters that describe the spatial pattern of L50\% around Tasmania $(\mathrm{L} 50 \%=112.422-10.266 \mathrm{Lat}+$ 2.733Long + (-41.876Lat $\times-146.406$ Long), where latitude and longitude around Tasmania are considered negative; Fig.1). While this model described most of the variation in $\mathrm{L} 50 \%$ between sites, it failed to capture all of the variation (Fig. 2). The model fit to observed data was poorest for sites 12 (Temma) to 24 (Port Davey), which are situated off the west to south west of the State.

The fitted logistic curve for SOM from the Maria Island MPA fell within the curves from surrounding areas, hence there was no evidence that increased density within the MPA influenced the size at onset of maturity (Fig. 3). Examination of confidence limits around these model fits supports this conclusion with overlap between the Maria Island MPA and other sites except Boy in the Boat (both L50\% and L95\%) and Hellfire Bluff (L95\%). Only one site, Boy in the Boat, had significantly higher SOM, which would be the expected pattern if higher density in the MPA suppressed growth and SOM. Estimates of size at onset of maturity from Crayfish Point MPA and Glenvar Point differed significantly at both the $50 \%$ and $95 \%$ maturity points. However,

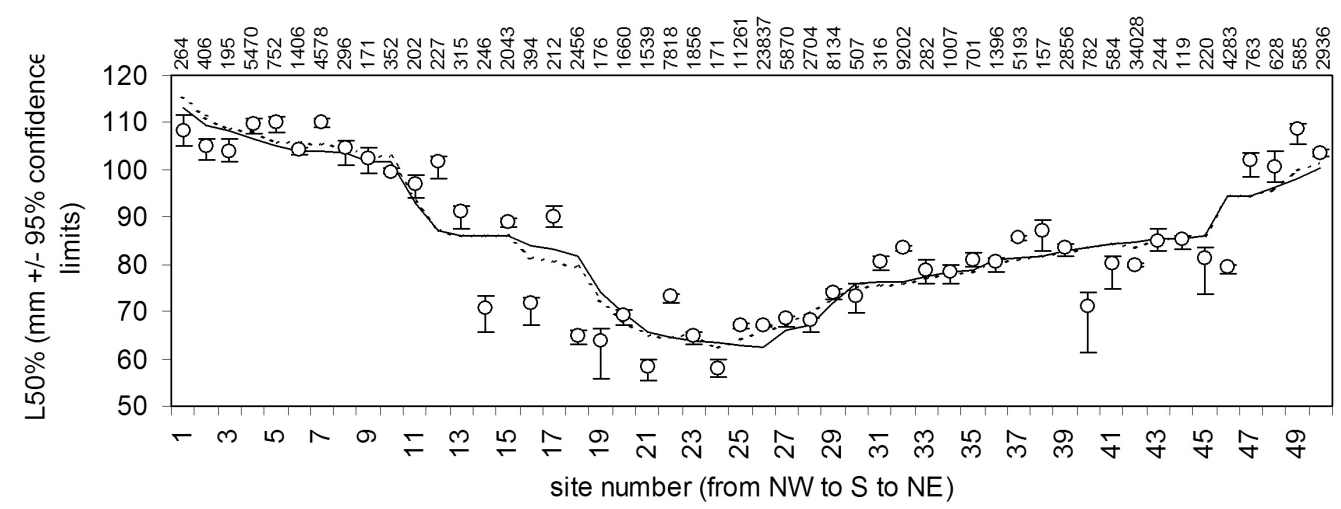

FIG. 2. - Actual estimates of L50\% of female southern rock lobsters Jasus edwardsii from 50 sites around Tasmania relative to model estimates. The fitted model includes the effects of latitude, longitude and their interaction. Confidence limits around point estimates were obtained by bootstrapping. Sample sizes for each site are shown above. 


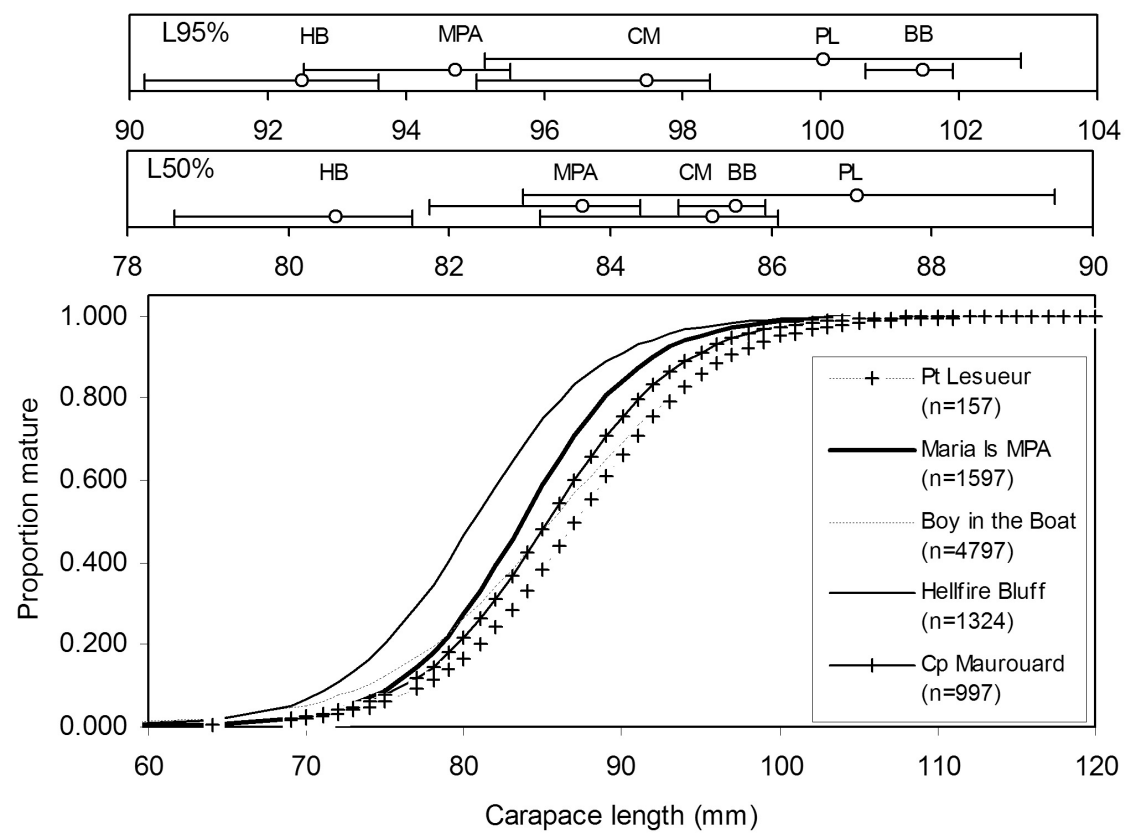

FIG. 3. - Modelled SOM at the Maria Island MPA and adjacent sites open to fishing within a $30 \mathrm{~km}$ radius. Upper plots show the $95 \%$ confidence limits for estimated L50\% and L95\% for the Maria Island MPA (MPA), Hellfire Bluff (HB), Cape Maurouard (CM), Boy in the Boat (BB) and Point Lesueur (PL). Carapace length is plotted on the X-axis in all cases.

the pattern of the two curves is the opposite to that which would suggest that onset of maturity is being supressed by the higher density (Fig. 4).

\section{DISCUSSION}

Spatial variation in SOM of female Jasus edwardsii in Tasmania was pronounced. It was mainly explained by change in latitude with a decline in SOM from north to south. At far northern sites, estimates of female SOM exceeded $110 \mathrm{~mm}$ $\mathrm{CL}$ while estimates for southern sites were often less than $65 \mathrm{~mm} \mathrm{CL}$. This quantification of spatial patterns in SOM will facilitate assessment of regional

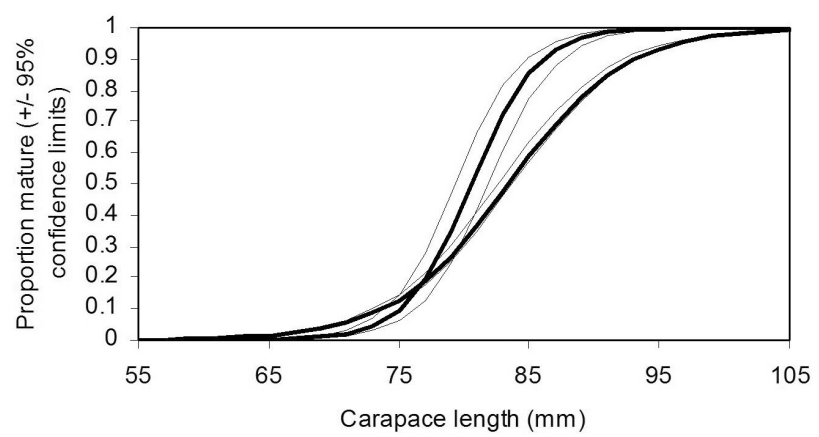

FIG. 4. - Size at onset of maturity estimates for female lobsters from the Crayfish Point MPA (curve to the right) and Glenvar Point (curve to the left) with 95\% confidence limits. These sites are within $20 \mathrm{~km}$. Glenvar point is heavily fished. egg production and thus increase the ability of fisheries managers to respond to regional issues. Jasus edwardsii are fished to the north of the Tasmanian region examined here but SOM does not continue to increase, which demonstrates that the linear model of SOM described here cannot be extrapolated beyond our data series. SOM for populations off western Victoria that are influenced by upwellings of cold, nutrient-rich water was estimated at $90 \mathrm{~mm}$ CL, while SOM for populations off eastern Victoria was estimated at $110 \mathrm{~mm}$ CL (Hobday and Ryan, 1997). The spatial pattern observed around Tasmania in SOM was equivalent to that described for growth of J. edwardsii around Tasmania by Punt et al. (1997), which is consistent with the hypothesis that SOM in female lobsters is age-specific rather than size-specific (Pollock and Goosen, 1991).

The current legal minimum length (LML) was effectively introduced in 1885 following a recommendation by Saville-Kent (1884). Despite the limited data available to Saville-Kent, his choice of LML appears remarkably appropriate, as a profitable and stable fishery has developed while the LML is higher than our estimates of L50\% for much of the State. Population modelling of $J$. edwardsii in Tasmania has also confirmed that the $105 \mathrm{~mm}$ LML is an appropriate statewide limit (Punt and Kennedy, 1997). While the current LML of $105 \mathrm{~mm} \mathrm{CL}$ appears a reasonable limit for the State as a whole, 
our results indicate that this approach of a single spatial regime is sub-optimal for maintaining regionally distributed levels of egg production. The current LML appears excessively conservative for southern regions while it provides little functional protection of egg production in far northern regions where the L50\% was greater than the LML. The extreme spatial variation observed here where L50\% almost doubles from south to north shows that improvements would be gained through some element of spatial management in the Tasmanian resource. Options include regional size limits or regional quotas.

While a model based on latitude and longitude provided close fits to SOM for most of the State, the fit from this simple model was poorest along the west to south west coast where residuals were greatest, and both positive and negative (Fig. 2). This implies greater local variability along this stretch of coast than in other regions. A candidate effect to explain this local variation is the substantially higher rainfall in this region relative to elsewhere in the State. River outfalls in this region have unusually low nutrient status and their exceptional tannin loadings greatly reduce algal photosynthesis and primary production (Edgar et al., 1999).

Although female SOM around Tasmania appears to change in a predictable way relative to longitude and latitude, these factors are not a mechanism for altering SOM, rather they are a proxy for some other factor such as lobster density or water temperature. Differences between regions are presumably a function of phenotype rather than genotype, given the prolonged larval development of this species $(>18$ months) and consequent dispersal over hundreds of kilometres (Chiswell and Booth, 2005). Amongst environmental factors that may be the cause of regional differences, water temperature appears a feasible candidate because it declines with increasing latitude and tends to be warmer off the south east coast than off the south west (Cresswell et al., 1983; Cresswell, 2000). That is, the spatial pattern in female J. edwardsii SOM is positively correlated with changes in water temperature around Tasmania. Remarkably, the opposite trend has been reported for New Zealand populations of J. edwardsii where SOM appears negatively correlated with temperature (Annala et al., 1980). That study spanned greater latitudes $\left(35^{\circ}-46^{\circ} \mathrm{S}\right)$ than reported here $\left(39.5^{\circ}-43.5^{\circ} \mathrm{S}\right)$ and also examined female SOM at numerous sites. Note that there has been no genetic difference detected between the Tasmanian and New
Zealand populations and it is believed that larval transport occurs between the regions (Booth et al., 1990; Ovendon et al., 1992).

Given the opposite and distinct patterns, how can the spatial patterns in female SOM around Tasmania and New Zealand be explained? Aside from temperature, a factor that is correlated with latitude in Tasmania is lobster density, with research catch rates of both legal and sub-legal sized lobsters generally over ten times higher in the south west than in the north west (Gardner et al., 2005a). Increase in density is expected to lead to reduced food availability and growth, which in turn is generally considered to reduce SOM (Breen, 1994; Sanchez Lizaso et al., 2000). This pattern has been observed in other Jasus species (J. lalandii (H. Milne Edwards) and J. tristani Holthuis; Beyers and Goosen, 1987; Pollock and Shannon, 1987; Pollock, 1991) and also in Nephrops norvegicus (L.) (Tuck et al., 2000).

We examined the effect of density on growth and SOM by comparing fished and unfished areas, but observed little change in SOM despite substantial differences in density. Insight into the effect of density on Tasmanian stocks of $J$. edwardsii is also available through historical accounts of fishers. For example, John Olaf Norling fished areas in the far north east of Tasmania prior to the 1950s and used to obtain very high catch-rates of around 1000 lobsters per day from 40 traps worked from a sail boat (Kerr, 1997). He reported that "those days the (lobsters) were very small and you had to measure them (to check if they were greater than the LML). As the years went on they got larger and larger" (Kerr, 1997). This account leads to a conclusion that contrasts with our results, that is, Tasmanian populations of $J$. edwardsii did appear to respond to a reduction in density from fishing. Changes in growth rate of $J$. edwardsii at different densities have also been detected through tag recapture data from fished regions in South Australia (McGarvey et al., 1999).

In New Zealand, there appears to be some evidence of effects of density on female SOM from the North Island with higher estimates of SOM from the lower density west coast relative to the east coast. However, SOM from the Leigh Marine Reserve estimated by MacDiarmid (1989; $87.5 \mathrm{~mm} \mathrm{CL}$ ) was greater than SOM estimates by Annala et al. (1980; $79 \mathrm{~mm} \mathrm{CL}$ ) from fished populations at Whitianga, which is around $100 \mathrm{~km}$ distant. In summary, the effect of density on SOM of J. edwardsii is unclear and warrants further research. A failing of many 
analyses of density dependent effects, including the analysis presented here, is that comparisons between sites with different densities are confounded by possible site differences. The effects of density on SOM would ideally be evaluated in a more formal manipulative design that includes samples both before and after density is altered (that is, a BACI design). Given current knowledge, there appears to be limited support for density of $J$. edwardsii being the mechanism responsible for the spatial trends in SOM in Tasmania and New Zealand.

The mechanisms regulating spatial variation in female SOM of J. edwardsii remain unclear and do not appear to be simply temperature or density alone. Other factors and interactions may be involved such as prey availability and prey type, shelter availability, predator interactions and intraspecific interactions. For example, growth rates in lobsters are influenced by social interactions (Thomas et al., 2003) and this appears to lead to a substantial reduction in female SOM of J. edwardsii in culture, even when supplied with excess food. The majority of female lobsters reared in tanks by Smith (2004) using water drawn directly from the Crayfish Point MPA produced eggs only two years after settlement and at $55 \mathrm{~mm} \mathrm{CL}$, yet our results from wild animals from the same MPA indicted an L50\% of around $85 \mathrm{~mm} \mathrm{CL}$.

Understanding the mechanisms regulating female SOM may be important for fisheries management where these processes can change over time, such as through changes in ecosystems, lobster density or water temperature. Such changes would be expected to alter the effect of fisheries management rules designed to maintain egg production. Improved spatial management of egg production appears to be an immediate challenge for the Tasmanian lobster fishery and will be facilitated by the patterns shown here.

\section{ACKNOWLEDGEMENTS}

Analyses presented in this paper relied on data collected from a range of projects over several years, usually with FRDC, DPIWE and Fishing Industry support. Especially important contributions since 1989 were made by Shane Fava, Craig Mackinnon, Alison Phillips, Jac Gibson, Jo Beukers-Stewart, Matt Francis, Fiona Ewing, Rod Pearn, Andrew Cawthorn and Graham Ewing.

\section{REFERENCES}

Annala, J.H., J.L. McKoy, J.D. Booth and R.B. Pike. - 1980. Size at the onset of sexual maturity in female Jasus edwardsii (Decapoda: Palinuridae) in New Zealand. N.Z. J. Mar. Freshw. Res., 14: 217-227.

Beyers, C.J. and P.C. Goosen. - 1987. Variation in fecundity and sexual maturity of female rock lobster Jasus lalandii in the Beguela ecosystem. S. Afr. J. mar. Sci., 5: 513-521.

Booth, J.D., R.J. Street and P.J. Smith. - 1990. Systematic status of the rock lobster Jasus edwardsii from New Zealand and $J$. novaehollandiae from Australia. N.Z. J. Mar. Freshw. Res., 24: 239-249.

Breen, P.A. - 1994. Population dynamics and stock assessment of lobsters: a review. Crustaceana, 67: 239-255.

Buxton, C.D., N. Barrett, M. Haddon, C. Gardner and G. Edgar. 2004. Evaluating the effectiveness of Marine Protected Areas as a fisheries management tool. Fisheries Research Development Corporation Final Report 1999/162. 384pp.

Chiswell, S.M. and Booth, J.D. - 2005. Distribution of mid- and late-stage Jasus edwardsii phyllosomas: implications for larval recruitment processes. N.Z. J. Mar. Freshw. Res., 39, 1157-1170.

Cresswell, G. - 2000. Currents of the continental shelf and upper slope of Tasmania. Pap. Proc. R. Soc. Tas., 133: 21-30.

Cresswell G.R., C. Ellyett, R. Legeckis and A.F. Pearce. - 1983. Nearshore features of the East Australian Current system. Aust. J. Mar. Freshw. Res., 34: 105-114.

Davis, G.E. and J.W. Dodrill. - 1989. Recreational fishery and population dynamics of spiny lobsters, Panulirus argus, in Florida Bay, Everglades National Park, 1977-1980. Bull. Mar. Sci., 44: 78-88.

Edgar, G.J. and N.S. Barrett. - 1999. Effects of the declaration of marine reserves on Tasmanian reef fishes, invertebrates and plants. J. exp. mar. Biol. Ecol., 242: 107-144.

Edgar, G.J., N.S. Barrett and P.R. Last. - 1999. The distribution of macroinvertebrates and fishes in Tasmanian estuaries. $J$. Biogeogr., 26: 1169-1189.

Gardner, C., S. Frusher and S. Ibbott. - 2000. Preliminary modelling of the effect of marine reserves on the catch, egg production, and biomass of rock lobsters in Tasmania. Tasmanian Aquac. Fish. Inst. Tech. Rep. No. 12, 36 pp.

Gardner, C., A. Hirst and M. Haddon. - 2005a. Tasmanian Rock Lobster Fishery 2003/2004. Tasmanian Aquac. Fish. Inst. Assess. Rep., 78 pp.

Gardner, C., D. Mills and S.D. Frusher. - 2005b. Does pleopod setation provide a measure of maturity in female southern rock lobsters Jasus edwardsii? Sci. Mar., 69: 123-131.

Haddon, M. - 2001. Modelling and Quantitative Methods in Fisheries. Chapman and Hall, London.

Hobday, D.K. and T.J. Ryan. - 1997. Contrasting sizes at sexual maturity of southern rock lobsters (Jasus edwardsii) in the two Victorian fishing zones: implications for total egg production and management. Mar. Freshw. Res., 48: 1009-1014.

Hobday, D., A.E. Punt and D.C. Smith. - 2005. Modelling the effects of marine protected areas (MPAs) on the southern rock lobster (Jasus edwardsii) fishery of Victoria, Australia. N.Z. J. Mar. Freshw. Res., 39: 675-686.

Kerr, G. - 1997. Of Men Boats and Crayfish: An Oral History of the Norling Family. Portland, Victoria: Mains'l Books.

MacDiarmid, A.B. - 1989. Size at onset of maturity and sizedependent reproductive output of female and male spiny lobsters Jasus edwardsii (Hutton) (Decapoda, Palinuridae) in northern New Zealand. J. exp. mar. Biol. Ecol., 127: 229-243.

McGarvey, R., G.J. Ferguson and J.H. Prescott. - 1999. Spatial variation in mean growth rates at size of southern rock lobster, Jasus edwardsii, in South Australian waters. Mar. Freshwat. Res., 50: 333-342.

Neter, J., M.H. Kutner, C.J. Nachtsheim and W. Wasserman. 1990. Applied Linear Statistical Models. 4th Ed. Irwin, Chicago.

Ovendon, J.R., D.J. Brasher and R.W.G. White. - 1992. Mitochondrial DNA analyses of the red rock lobster Jasus edwardsii supports an apparent absence of population subdivision throughout Australasia. Mar. Biol., 112: 319-326.

Pollock, D.E. - 1991. Spiny lobster at Tristan da Cunha, South 
Africa: inter island variation in growth and population structure. S. Afr. J. mar. Sci., 10: 1-12.

Pollock, D.E. and P.C. Goosen. - 1991. Reproductive dynamics of the two Jasus species in the south Atlantic region. S. Afr. J. mar. Sci., 10: 141-147.

Pollock, D.E. and L.V. Shannon. - 1987. Response of rock lobster populations in the Benguela ecosystem to environmental change - a hypothesis. S. Afr. J. mar. Sci., 5: 887-899.

Punt, A.E. and R.B. Kennedy. - 1997. Population modelling of Tasmanian rock lobster Jasus edwardsii, resources. Mar. Freshw. Res., 48: 967-980.

Punt, A.E., R.B. Kennedy and S.D. Frusher. - 1997. Estimating the size transition matrix for Tasmanian rock lobster, Jasus edwardsii. Mar. Freshw. Res., 48: 981-992.

Sanchez Lizaso, J.L., R. Goni, O. Renones, J.A.Garcia Charton, R. Galzin, J.T. Bayle, P. Sanchez Jerez, A. Perez Ruzafa and A.A. Ramos. - 2000. Density dependence in marine protected populations: a review. Environ. Conserv., 27: 144-158.

Saville-Kent, W. - 1884. Report to his Excellency Sir George Cumine Strahan, Governor over the Colony of Tasmania on the fisheries of the Colony. 38 pp.
Smith, G.G. - 2004. Maternal and nutritional factors affecting larval competency in the spiny lobster, Jasus edwardsii. $\mathrm{PhD}$ thesis, Univ. Tasmania.

Thomas, C.W., C.G. Carter and B.J. Crear. - 2003. Feed availability and its relationship to survival, growth, dominance and the agonistic behaviour of the southern rock lobster, Jasus edwardsii, in captivity. Aquaculture, 215: 45-65.

Tuck, I.D., R.J. Atkinson and C.J. Chapman. - 2000. Population biology of the Norway lobster, Nephrops norvegicus (L.) in the Firth of Clyde, Scotland. II. Fecundity and size at onset of sexual maturity. ICES J. Mar. Sci., 57: 1227-1239.

Turner, K., C. Gardner and R. Swain. - 2002. Onset of maturity in male southern rock lobsters Jasus edwardsii in Tasmania, Australia. Invert. Reprod. Dev., 42: 129-135.

Ziegler, P.E., C.R. Johnson, S.D. Frusher and C. Gardner. - 2002. Catchability of the southern rock lobster. II. Effects of size. Mar. Freshw. Res., 53: 1149-1159.

Scient. ed.: C. Zeng

Received November 25, 2005. Accepted April 25, 2006.

Published online July 6, 2006. 